\title{
Televised Political Advertising in Egypt: The Case of 2012 Parliamentary Elections
}

Khaled Gaweesh, Ph.D.*

\section{Introduction}

Political advertising is the sole form of communication that is completely controlled by the political candidates or parties without any form of interpretation or filtering by media (Kaid, 2004). The televised political advertising is considered the most dominant in elections and the most solid evidence for this is the remarkable amount of money spent on televised political advertising (MarmorLavie and Weimann, 2008).

Although political advertising is a well known phenomenon in Western democratic countries, the situation is totally different in the majority of Arab countries including Egypt. Perhaps this was the first time for Egyptians to witness real political ads by competing political parties. There has been valuable research done on political advertising in many countries especially in Europe and the United states but there is no such research in the Arab world because the phenomenon itself did not exist. Despite this fact, knowledge levels on political advertising among many marketing academics and practitioners, who are not directly involved with the study or practice of political advertising, are not the same as they are on other types of advertising and promotions issues (Taylor, 2010).

\footnotetext{
${ }^{*}$ Associate Professor Department of PR \& Advertising, Faculty of Mass Communication, Cairo University

The Scientific Journal of Department of Public Relations and Advertising 
Political advertising needs more attention by individuals trained in advertising and promotion (Taylor, 2010). If this is the case in societies with long history of political advertising, we can imagine how much attention needed in the Arab world where the practice of political advertising is still in the childhood stage. Most of political advertising research during 2010 appeared in non-advertising journals (Taylor, 2010). There is a need for more research on how principles of advertising and promotion apply to the political area.

\section{Political Background:}

After the $25^{\text {th }}$ of January revolution that ousted President Hosni Mubarak, the Supreme Council of the Armed Forces (SCAF) dissolved the Parliament of Egypt. A constitutional referendum was held in Egypt on 19 March 2011. More than 14 million (77\%) were in favor, while around 4 million (23\%) opposed the changes; $41 \%$ of 45 million eligible voters turned out to vote. The approved constitutional reforms included a limitation on the presidency to at most two "fouryear" terms, judicial supervision of elections, a requirement for the president to appoint at least one vice president, a commission to draft a new constitution following the parliamentary election, and easier access to presidential elections by candidates.

The reforms were recognized by both sides to increase democratic safeguards, but opponents argued that they did not go far enough and that an election held too soon could favor the wellorganized Muslim Brotherhood and members of the former ruling National Democratic Party of Hosni Mubarak. Supporters cited 
concerns that waiting too long could increase the chances of the military regaining power or risk destabilization before an election.

A parliamentary election was planned within the next six months, with groups already working to create new political parties, promote candidates and increase turnout among their supporters. The parliamentary elections were scheduled to be held in September 2011, but were postponed amid concerns raised by newly established parties to have more time to be prepared. The parliamentary elections to the People's Assembly (Majlis Al Shaab) of Egypt were held from November $28^{\text {th }}, 2011$ to January $11^{\text {th }}, 2012$. The elections to the Consultative Council (Majlis Al shura), the second body-with less power- in the Egyptian parliamentary system, were held from January $29^{\text {th }}, 2012$ to February $22^{\text {nd }}, 2012$.

These elections were important because the elected members of both legislative bodies will choose the 100 members committee who will set the new constitution of Egypt.

The elections have been held according to the new electoral law issued by $S C A F$. Two thirds of the seats have been elected by party-list proportional representation and one third by first-past-thepost FPTP.

\section{Research Problem:}

It has been the first free and democratic parliamentary elections in Egypt since at least sixty years. Although political advertising is being used in many countries around the world, the author think that this is the first time to be practiced in Egypt. 
Although political advertising has been used somehow in many parliamentary and presidency elections in Egypt before, the fact is that in all previous elections there was no real freedom, integrity, neither transparency. There was no full, real judicial supervision neither monitoring by NGO's. In sum, there were no real elections; it was like a play with the Democratic National Party $D N P$ (or other political bodies with different names which had been inherited by $D N P$ ) playing the role of the winner all the time.

In 2011-2012 elections, the political advertising has been used by many political parties as part of their campaigning. For the first time in Egypt, Egyptians people watch different political ads with no constraints as they watch different ads for many products. No one has known how the results of the elections would be exactly; it is fair and democratic for the first time in the lives of the voters. In fact, there was no fraud in these elections as expressed by the majority of observers, analysts and rivals.

Through analyzing the televised political ads aired by the Egyptian political parties during 2011-2012 Parliamentary elections, this research paper tests the applicability of the Functional Theory (Benoit, Pier \& Blaney, 1997) of political campaign discourse on political advertising in Egypt. This paper also seeks to monitor the differences among Egyptian political parties (if any) in their use of TV ads, in addition to discovering the slogans and appeals used by these parties in their TV ads. 


\section{Literature Review:}

\section{Functions of Political advertising: Theoretical Framework}

This study tests the applicability of the Functional Theory of political campaign discourse, which has been developed by Benoit and his associates (Benoit, Pier \& Blaney, 1997), on political advertising in Egypt. This theory indicates that there are three functions of political advertising: first, acclaims (positive statements), where the candidate can engage in acclaiming or self-praise (Benoit, Blaney \& Pier, 1998). The greater the benefits or advantages of one candidate, the more likely that person will appear preferable compared with opponents. Second, attacks (negative ads), where candidates can attack their opponents, as voters become aware of more costs or disadvantages to opponents, they should appear less desirable to voters. The candidate- who attacks- hopes for a net increase in desirability as the attack is intended to reduce the opponent's preferability. Third, defenses (refutation of attacks): where candidates who have been subjected to attack can defend against those attacks. The smaller the costs or disadvantages, the more likely that candidate will appear preferable to opponents. According to Benoit and his associates (Benoit, Delbert, Sudbrock, and Vogt, 2010), these three options comprise an informal form of cost-benefit analysis, providing information that can help persuade the voter to prefer one candidate. Cost-benefit analysis does not mean that voters systematically quantify the impact of acclaims, attacks, or defenses to decide their voice choice (Benoit, Delbert, Sudbrock, and Vogt, 2010). The costbenefit analysis is meant to indicate that acclaims tend to increase 
one's benefits, attacks may increase an opponent's costs, and defenses can reduce one's costs.

\section{Use of Appeals in Political Advertising}

The three functions (acclaims, attacks, and defenses) can occur on two topics: first, policy (issue) or character (image). Policy utterances concern governmental actions or problems that are amenable to governmental action. Issues are usually associated with rational thinking, cognition, and politicians' policy statements on hardcore topics. Character comments concern the candidates as individuals. Conversely, images are related to emotions, sound-bites, and candidates' characteristics and qualities (Kaid, 2004). Political advertising researchers have referred to the "issue-versus-image debate." According to the classic democratic voting theory (Berelson, 1966), voters make their voting decisions rationally through weighing the pros and cons of each political party or candidate. The use of "image" contradicts Berelson's approach. When voters base their decisions on image (emotional reactions stimulated by emotional appeals) the rational path is totally neglected (Goren, 1997). Many people argue that emotionally based decisions can be very dangerous, especially when politicians and political parties use voters' emotional reactions to advance their own selfish agendas (Marmor-Lavie and Weimann, 2008).

The "topic" is related to the appeals used in political advertising. The appeals may be rational (related to "issue") or emotional (related to "image"). Emotional appeal was defined as "any 
communication that is intended to elicit an emotional response from some or all who receive it" (Brader, 2006, pp. 68-69). Previous research focused on either the emotional content of ads or the effects of such emotional content. Studies have explored both positive and negative emotional appeals in ads. Through content analysis, some studies explored positive emotional appeals such as compassion, ambition, nostalgia, reassurance, trust, hope, pride, intimacy (Kern, 1989), studied pride, compassion, amusement, and enthusiasm (Brader, 2006).

\section{The Political Slogan}

In politics, the slogan is seen as one of the basic elements used in an electoral campaign in order to differentiate the political party from its opponents, and is defined as: "a short statement about the reasons why a candidate should be elected or why the voters should vote for your message" (Shaw, 2004, p.37), or "a motto or phrase that expresses a goal or an aim, used for a political purpose" (Al-Haq \& Hussein ND), A successful slogan will motivate the electors and will influence them in directing their vote towards a certain candidate. The slogan offers the devoted voters a reason to maintain their political behavior. To the undecided, the slogan, along with other components of the electoral offer, should give sufficient reasons to choose the respective candidate. A well thought slogan should bring only benefits to the political party, and these benefits are summed up in the people's votes. The slogan should express the electoral message that emphasizes the different sides of the electoral offer. It should be the concentrated information of the electoral platform. A well-crafted 
slogan will highlight the differences between the candidate and his opponents and will give the argument for voting him (Hosu and Pavelea, 2010). As regards the typology of the political slogan, some authors distinguish between four types: the imperative slogan: implicitly asks for an action or commands the company to do something; the descriptive slogan: describes the key feature or benefit of the candidate or party; the superlative slogan: exaggerates the message but in a way that makes a point and is something you believe to be true; and the provocative slogan: makes the listener or the viewer think or reflect on the presented situation (Hosu and Pavelea, 2010).

Because the political battle was mainly between two wings: the political parties with religious background and their counterparts with nonreligious background, this paper was interested in studying this variable (ideological background) in addition to other variables included in the Functional Theory.

\section{Research Hypotheses \& Questions:}

Based on Functional Theory predictions, acclaims will be more common than attacks (Benoit 2007). Defenses are expected to be rare because they occur when a candidate is weak, refuting an attack may inform or remind voters of potential weakness, and refuting attacks may create the impression that the candidate is reactive rather than proactive.

H1: Political advertisements will acclaim more than they attack and attack more than they defend. 
Functional Theory predicts that policy (issue) will receive a heavier emphasis than character (image) in political advertising.

The electoral system (the elections law) has an impact on the "topic" of political advertising. In the party-list proportional representation, it seems that "policy (issue) is more important than character (image).

H2: Political advertisements will discuss policy more than character.

Political experts constantly search for ways to increase the emotional bonds between candidates and voters, a large number of studies have shown that emotion can play a substantial role in political attitudes and political communication (Marmor-Lavie and Weimann, 2008).

Emotional strategies are one of the core elements of the entire advertising campaign; each party or situation involves a different emotion (Goldberg,1994). Previous studies show that religious parties, much more than nonreligious parties, tend to stimulate emotions of warm-heartedness and try to generate feelings of love, intimacy, and closeness among their members in an attempt to persuade (MarmorLavie and Weimann, 2006)

Political parties with religious background tend to rely on emotions when addressing masses while other political parties with non-religious background tend to rely less on emotions. 
H3: Political parties with religious background will use emotional appeals more than parties with nonreligious background.

As religion beliefs relate to emotions, it is expected this will affect the ad messages of religious political parties.

H4: Political parties with religious background will use religious appeals more than parties with nonreligious background.

The research seeks to answer four additional questions as follows:

RQ1: Is there a difference among political parties in the use of "functions"?

RQ2: Is there a difference among political parties in "topics"?

RQ3: Did the ads use slogans? What types of slogans have been used?

RQ4: What are the appeals used in Egyptian political advertising?

\section{Methodology:}

Television spots were obtained by downloading from YouTube, TV, and political parties' websites. The total of 50 ads (all available ads) has been analyzed using quantitative content analysis. The ad has been used as a unit of analysis with more focus on the verbal message. The analysis tool has been developed according to the research hypotheses and questions. It includes the ten following categories:

1. Political party.

2. Tone (function):

a. Acclaims: portray the candidate favorably. Positive statements. 
b. Attack: portray the opposing candidate unfavorably-negative.

c. Defenses: explicitly respond to prior attack on the sponsoring candidate-refutation of attacks.

d. Other: all previous does not apply (to be mentioned)

3. Topic:

a. Policy (issue): remarks concern governmental action and problems amendable to such action.

b. Character (image): remarks address properties, abilities, or attributes of the candidate.

4. Policy (issues):
a. Past deeds
b. Future plans
c. General goals

5. Policy (issues):
a. Economic
b. Politics
c. Social
d. Education
e. Health
f. More than one
g. Other (to be mentioned)

6. Format:
a. Humor
b. Slice of life 

c. Testimonial
d. Demonstration
e. Problem \& solution
f. Talking head
g. Musical
h. Nostalgia
i. Celebrities
j. Cartoon
k. Other (to be mentioned)

7. Slogans:
a. Yes
b. No

8. Slogan type:

a. Impressive: implicitly asks for an action

b. Descriptive: describes the key feature or benefit of the political party

c. Superlative: exaggerates the message but in a way that makes a point and is something you believe to be true.

d. Provocative: makes the viewer thinks or reflects on the presented situation.

9. Appeals used:

a. Emotional (youth, dreams, music, revolution, corruption)

b. Rational 
10. Emotional appeals used:
a. Nationalism, identity, and pride
b. Religious
c. Youth, future, hope
d. Compassion
e. Nostalgia
f. Enthusiasm \& revolution
g. Fear
h. Humor

Inter-coder reliability ranged from 0.87 to 1.00 for different categories.

Table (1)

Ads per political party

\begin{tabular}{|c|c|c|}
\hline Political Party & $\begin{array}{c}\text { Number of } \\
\text { ads }\end{array}$ & Percent \\
\hline 1. Alkotlah Almasreia & 11 & $22 \%$ \\
2. Al Wafd & 11 & $22 \%$ \\
3. Al horreia waladala & 7 & $14 \%$ \\
4. Althawra Mostamerra & 4 & $8 \%$ \\
5. Al Noor & 4 & $8 \%$ \\
6. Aladl & 4 & $8 \%$ \\
7. Alkotla and Almasreieen Alahrar & 2 & $4 \%$ \\
8. Althawra Almasreiah & 1 & $4 \%$ \\
9. Almasreieen Al Ahrar & 1 & $2 \%$ \\
10. Al Wasat & 1 & $2 \%$ \\
11. Almohafezeen & 1 & $2 \%$ \\
12. Almasry Aldemocraty Alegtemaei & 1 & $2 \%$ \\
13. Alsalam Aldemocraty & 50 & $100 \%$ \\
\hline Total & &
\end{tabular}




\section{Results:}

The results for each hypotheses and research question will be presented in the order in which they were developed above. The first hypothesis was confirmed, as acclaims were the most common function in these ads ( $86 \%$ singly), followed by attacks (2\% singly and $8 \%$ combined with acclaims in the same ad), and the defenses $(2 \%$ combined with acclaims) and educational (2\%, teaching voters how to vote). This distribution of functions was significant (chi-square $=136.8$ $(\mathrm{df}=4), \mathrm{P}<0.0001$.

\section{Table 2}

\section{Results of hypothesis 1}

\begin{tabular}{|l|l|l|}
\hline Tone (function) & frequency & Percent \\
\hline Acclaims & 43 & $86 \%$ \\
Attacks & 1 & $2 \%$ \\
Acclaims \& attacks & 4 & $8 \%$ \\
Acclaims \& defenses & 1 & $2 \%$ \\
Educational & 1 & $2 \%$ \\
\hline total & 50 & $100 \%$ \\
\hline
\end{tabular}

$$
\text { Chi-square }=136.8(d f 4) P<.0001
$$

Hypothesis 2 predicted that advertisements will discuss policy more than character. In 2012 Parliamentary elections, ads discussed policy more character (54\% to $30 \%$ ). The relative emphasis on policy versus character was statistically significant (chi- square $=30.32(d f=3), \mathrm{P}<.0001$ 
Table 3

Results of hypothesis 2

\begin{tabular}{|l|l|l|}
\hline Topic & frequency & Percent \\
\hline Policy (issue) & 27 & $54 \%$ \\
Character (image) & 15 & $30 \%$ \\
Both & 7 & $14 \%$ \\
None & 1 & $2 \%$ \\
\hline total & 50 & $100 \%$ \\
\hline
\end{tabular}

Chi-square $=30.32($ df 3) $P<.0001$

Hypothesis 3 predicted that political parties with religious background will use emotional appeals more than political parties with non-religious background. The results show that political parties with religious background used emotional appeals in $90.9 \%$ of the ads (out of 11 ads) while the political parties with non-religious background used emotional appeals in $43.5 \%$ of the ads (out of 39 ads). The total number of ads used emotional appeals is 27 ads (54\%) which indicates that political ads, in general, tended to use emotional appeals more than rational appeals. The result is statistically significant: Chi-square $=32.577(d f=8), \mathrm{P}<.0001$.

Table 4

Results of hypothesis 3

\begin{tabular}{|c|l|l|l|}
\hline & \multicolumn{2}{|l|}{ Party Background } & total \\
\hline Appeal used & Religious & Non-religious & \\
rational & 1 & 22 & 23 \\
emotional & 10 & 17 & 27 \\
total & 11 & 39 & 50 \\
\hline
\end{tabular}

Total number of ads used emotional appeals: 27

The Scientific Journal of Department of Public Relations and Advertising 
Chi-square $=32.577(d f 8) \quad p<.0001$

Hypothesis 4 predicted that political parties with religious background will use religious appeals more than political parties with non-religious background. The result supported this hypothesis: among all ads used emotional appeals (27 ads), there are only 4 ads used religious appeals, all of them used by political parties with religious background. The result is statistically significant: Chi-square $=7.983(d f=1), \mathrm{P}<.005$.

\section{Table 5}

\section{Results of hypothesis 4}

\begin{tabular}{|r|l|l|l|}
\hline & \multicolumn{2}{|l|}{ Party Background } & total \\
\hline Emotional appeal used & Religious & Non-religious & \\
Religious & 4 & 0 & 4 \\
Non-religious & 6 & 17 & 23 \\
total & 10 & 17 & 27 \\
\hline
\end{tabular}

Total number of ads used emotional appeals: 27

Chi-square $=7.983(d f 1) \quad p<.005$

Research question 1 asked if there is a difference among political parties in the use of "functions". Results show that there is no difference among ads for all political parties included in the study in the use of "functions" (acclaims, attacks, defenses).

Research question 2 asked if there is a difference among political parties in "topic". Results show that there is no difference among political parties in the topic (policy, issue). 
Research question 3 was about slogans and their types. The results show that 42 ads $(84 \%)$ of the analyzed ads used slogans. Table 6 shows the types of slogans used as follows:

\section{Table 6}

\section{Types of slogans}

\begin{tabular}{|l|l|l|}
\hline Type of slogan & Frequency & Percent \\
\hline Descriptive & 21 & $50 \%$ \\
Imperative & 13 & $31 \%$ \\
Provocative & 6 & $14.3 \%$ \\
Superlative & 2 & $4.7 \%$ \\
\hline Total & 42 & $100 \%$ \\
\hline
\end{tabular}

Research question 4 asked about the appeals used in Egyptian political advertising. The results show that $54 \%$ of the ads used emotional appeals versus $46 \%$ used rational appeals. Among the emotional appeals used: $14.8 \%$ are religious and $85.2 \%$ are nonreligious (See Table 7)

\section{Table 7}

\section{Emotional appeals used}

\begin{tabular}{|l|l|l|}
\hline Emotional appeal & frequency & percent \\
\hline Nationalism, identity and pride & 6 & $22.2 \%$ \\
Youth, future and hope & 5 & $18.5 \%$ \\
Religious & 4 & $14.8 \%$ \\
compassion & 3 & $11.1 \%$ \\
Nostalgia & 3 & $11.1 \%$ \\
Enthusiasm \& revolution & 3 & $11.1 \%$ \\
Fear & 2 & $7.4 \%$ \\
humor & 1 & $3.7 \%$ \\
\hline total & 27 & $100 \%$ \\
\hline
\end{tabular}




\section{Conclusions and Implications:}

The research results support the Functional Theory of political campaign discourse. All three functions are capable of persuading voters that a candidate is preferable to one's opponent. Acclaims have no disadvantages but it seems that voters dislike mudslinging (Merritt, 1984). This discourages candidates from attacking too heavily. Defenses have three potential drawbacks. First, opponents are likely to attack where the opponent is weak, which means that defending against an attack will usually take a candidate "off-message". Second, defenses are likely to sound reactive rather than proactive and candidates may not wish to encourage this impression. Third, a candidate must identify an attack in order to refute it. This means that when a candidate mentions an attack in preparation for the defense he or she may remind or inform voters of a potential weakness. So, it is reasonable to expect that acclaims would be more frequent than attacks and attacks more common than defenses.

Public opinion poll data (in the US) reveals that, in multiple campaigns, more voters reported that policy was a more important determinant of their vote than character (Benoit, 2003; Brazeal and Benoit, 2001). Thus, if voters believe policy is more important, this could encourage candidates to emphasize policy more than character in their ads.

On the other hand, the theory argues that the voter is "rational", taking his/her decision on an informal form of cost-benefit analysis. The economic status of the voters has been neglected, in the Egyptian case 
the phenomena of "buying" votes has been observed. Some political parties offered money to voters to make them vote for these parties exploiting their poverty and need for money. This research proposes additions to the theory. First, the cultural variable (collective versus individual cultures) should be considered as influencing the functions of political advertising. In collective cultures, it is immoral to attack others or even talk about them especially when they are not attendants. The author can use this cultural value to explain why Egyptian candidates did not use attacking function in their ads. Second, the religious variable should be included in studying political advertising in Islamic countries because religion is an essential factor in affecting attitudes and behaviors. Third, the author suggests adding another function to political advertising which is "education" especially when it comes to societies new to democracy and with high rate of literacy. The last addition, the political and electoral systems should be tested as independent variables that influence the topic of political advertising, as party-list proportional representation makes "policy" more important than "character".

Political advertising in Egypt is still in the childhood stage. Although Egypt witnessed real democratic experiences and free elections before 1952, these practices have stopped since 1952. It is obvious that the present political parties do not have sufficient resources neither experience to use political TV advertising; only 13 parties (out of 60 political parties in Egypt at the time of conducting the research-Guide of Egyptian Political Parties,2011) used political TV advertising with total of 50 spots. $58 \%$ of these ads have been done by only three 
parties, which indicate the necessity for using political TV advertising especially in a country with high rate of literacy, poverty, and suffering from weak political movement for almost 60 years.

One of the interesting results is the appearance of what could be called "educational" function of political advertising. In this type of content, the function of the ad was to educate the voters about the election and voting processes, which should inspire the politicians, especially in newly established democracies, about the importance of educating people the culture of modern democracy.

The political parties with religious background relied more than parties with nonreligious background on emotional appeals especially religious ones. The insertion of religion in politics hurts the democracy and the whole political life since these practices give theocracy to the religious parties and put them over their rivals who do not use the same appeals. The religious appeals used in the campaign discourse of religious parties were crucial in their win in these elections. 


\section{References}

- Al-Haq, F. A. \& Hussein A. A. The Slogans of the Tunisian and Egyptian Revolutions: A Sociolinguistic Study. [URL: http://media.leidenuniv.nl/legacy/fawwaz.pdf], accessed on March 23, 2015.

- Benoit, W. L. Communication in Political Campaigns. New York. Peter Lang, 2007.

- $\quad$ Benoit, W. L. "Political Campaign Discourse as a Causal Factor in Election Outcome." Western Journal of Communication 67, 1(2003): 97-112.

- Benoit, W. L \& Airne, D. "Non-presidential Advertising in Campaign 2004." Human Communication 12, 1 (2009):91-117.

- $\quad$ Benoit, W. L., Delbert, J., Sudbrock, L A., \& Vogt, C. "Functional analysis of 2008 Senate and gubernational TV spots." Human Communication 13, 2 (2010):103-125.

- Benoit, W. L., Blaney, J.R. \& Pier, P. M. Campaign '96: A Functional Analysis of Acclaiming, Attacking, and Defending. Westport, CT. Praeger, 1998.

- Benoit, W. L., Pier, P. M., \& Blaney, J.R. "Sustainable Development" in Visual Imagery: A Functional Approach to Televised Political Spots: Acclaiming, Attacking, Defending." Communication Quarterly 45, 1(1997):1-20.

- Berelson, B. "Democratic Theory and Public Opinion." In Reader in Public Opinion and Communication, B. Berelson \& M. Janowitz, eds. New York: Free Press, 1966.

- Brader, T. Campaigning for Hearts and Minds: How Emotional Appeals in Political Ads Work. Chicago. University of Chicago Press, 2006.

- Brazeal, L. M., \& Benoit, W. L. "A functional Analysis of Congressional Television Spots, 1986-2000.” Communication Quarterly 49, 4(2001): 436454.

- Daleel Al Ahzab Al Seyasia Al Masrieah. [URL: http:www.eip.gov.eg/Directories/Directory.aspx?id=56], accessed on December 29, 2011.

- Goldberg, G. The Israeli Voter, 1992. Jerusalem. Hebrew University Magnes Press, 1994.

- Goren, P. "Gut-level Emotions and the Presidential Vote." American Politics Quarterly, 25, 2(1997): 203-229.

- Hosu, I. \& Pavelea, A. "The Analysis of the Candidates' Slogans in the Romanian Presidential Campaign-November 2009." Journal of Media Research 6, 1 (2010): 18-30.

- Kaid, L.L. "Political Advertising." In Handbook of Political Communication Research, L.L. Kaid, ed. Hillsdale, NJ: Erlbaum, 2004.

- Kern, M. 30 Second Politics: Political Advertising in the Eighties. New York: Praeger, 1989. 


\section{Televised Political Advertising in Egypt}

- Marmour-Lavie, G., \& Weimann, G. "Measuring Emotional Appeals in Israeli Election Campaigns." International Journal of Public Opinion Research 18, 3 (2006): 318-339.

- Merrit, S. "Negative Political Advertising: Some Empirical Findings." Journal of advertising 13, 3(1984): 27-38.

- Shaw, Catherine. The Campaign Manager: Running and Winning Local Elections. Westview Press, 2004.

- Taylor, C. R. "Campaigning for More Research on Political Advertising." International Journal of Advertising 29, 5 (2010): 681-685. 